\title{
Taking the challenge for real food: Student engagement in procuring sustainably produced food on campus
}

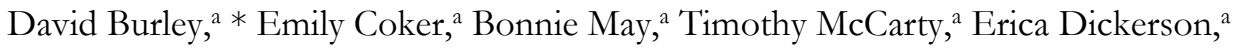 \\ Benny Milligan, ${ }^{a}$ Danaty Moses, ${ }^{a}$ Sole Sanchez, ${ }^{a}$ and Rick Hortman ${ }^{a}$ \\ Southeastern Louisiana University
}

\begin{abstract}
Submitted August 26, 2015 / Revised January 8, June 13, and August 17, 2016 / Accepted August 17, 2016 /
Published online December 5, 2016

Citation: Burley, D., Coker, E., May, B., McCarty T., Dickerson, E., Milligan, B., Moses, D., Sanchez, S., \& Hortman, R. (2016). Taking the challenge for real food: Student engagement in procuring sustainably produced food on campus. Journal of Agriculture, Food Systems, and Community Development, 7(1), 71-87. http://dx.doi.org/10.5304/jafscd.2016.071.011
\end{abstract}

Copyright (C) 2016 by New Leaf Associates, Inc.

\begin{abstract}
In the fall of 2011, a graduate seminar in applied environmental sociology at a southern university in the U.S. took on a project to help an undergraduate student environmental organization obtain local and sustainably produced food for the university cafeteria. The aim was for our seminar to use community-based research (CBR) to help Reconnect, the student club, drive social change. An important objective was for the seminar students to apply their academic skills to helping the student club while acquiring the new skills developed through engaging in social change. In
\end{abstract}

a Sociology and Criminal Justice Department, Southeastern Louisiana University.

* Corresponding author: David Burley, Sociology and Criminal Justice Department, Southeastern Louisiana University; 10686; Hammond, Louisiana 70402 USA; +1-985-549-5037; david.burley@selu.edu this reflective essay, we share our experience as a team of practitioners utilizing a community-based research approach in working with an undergraduate student group to launch a campaign to get local and sustainably produced food into the university cafeteria. During the project, we encountered many challenges yet had many accomplishments. For instance, there was resistance from the university's corporate food vendor, which ultimately prevented Reconnect from realizing local and sustainable food in the university cafeteria. However, we helped Reconnect build capacity for the initiative and catalyzed other institutional successes including laying the groundwork for a permanent farmers market on campus.

\section{Keywords}

Community-Based Research; Local Food Systems; Sustainability; Student Engagement; Transnational Corporations; Farmers Markets; Social Change 


\section{Introduction}

Could we get locally and sustainably produced food into our university cafeteria? Our graduate seminar in Applied Environmental Sociology took on this question in order to assist an undergraduate student environmental organization at Southeastern Louisiana University that was working toward this goal in partnership with two small, local minority farmer cooperatives. Our aim was to use community-based research (CBR) to help the student club achieve its goals and produce social change (Strand, Marullo, Cutforth, Stoecker, \& Donohue, 2003). Our project with Reconnect took place during the fall of 2011, but the student club had been involved in this endeavor since the previous spring and was loosely collaborating with the Real Food Challenge (RFC). RFC is a national student-run campaign to shift 20\% (approximately US\$1 billion) of university food budget money away from industrial food and toward local, fair, sustainable, and humane food by 2020 (Real Food Challenge [RFC], n.d.). This proved not to be easy at a university where most students are commuters, where the corporate vendor for food operations is resistant to change, and where food issues, especially the social and environmental issues that surround them, are not well understood.

Yet, the students of Reconnect believed that there was opportunity for change. They thought that if they could educate students on campus about the issues (such as promoting local, sustainably produced food), then their campaign would get widespread support and their goals could be reached. Reconnect, being a small student group, needed our help. In order to assist the student club, we sought to increase campuswide support for the program while the graduate students in our seminar put the skills they were learning in class into practice. In collaboration with Reconnect, we developed an educational campaign with a campus farmers market as the signature event, to build capacity for Reconnect's initiative. Thus, the aim of our reflective essay is to assess how we shared information about the campaign with the campus community, helped create a constituency for Reconnect and its goals, and what we learned through this process of assisting in social change.

\section{Literature Review}

\section{Transnational Corporations and the Food System}

The theoretical perspective we chose for this project analysis is the "treadmill of production" (Schnaiberg, 1980). This view, common in environmental sociology, sees environmental decline and the marginalization of labor as the result of increased competitive pressure for production. According to this theory, companies try to produce goods more cheaply than others. "Merely making a profit isn't good enough. A firm continually needs to maximize profits or investors will withdraw their support and put their resources in a firm that does" (Bell, 2012, p. 69). The treadmill is driven by ever-increasing competition and production from which returns to capitalprofit_-decline over time (Bell, 2012). For those who take this view, the primary barrier to local food procurement for institutions of any kind is the transnational corporation (TNC) (Martin \& Andrée, 2012). TNCs build capital by centralizing management structures and supply chains. The larger they grow, the further they reach with their mandate for an economically efficient model of "ready to eat" food (Martin \& Andrée, 2012). Due to the interaction between competition among TNCs and their directive to continually build capital, the sourcing and preparation of local foods is considered economically inefficient. Small-scale food processing that targets local markets would increase labor and procurement costs, creating an economic disadvantage compared to centralized TNCs. The power that TNCs exert globally contributes to the industrialization of food production by promoting monoculture farming and the extensive use of synthetic fertilizers and pesticides, which, at least in some instances, diminishes nutritional value (see Estabrook, 2012, for the example of tomatoes). Industrialization also tends to homogenize culinary traditions while degrading rural infrastructure because of centralized production and processing (Hendrickson \& Heffernan, 2002).

However, TNCs do not operate independently or in a totally autocratic manner. Changing political and economic structures contribute to (and sometimes inhibit) their ability to hold the majority of 
institutional foodservice contracts. Their historical rise during and after World War II is well documented by Martin and Andrée (2012). Today, three TNCs control the majority of global food services: Aramark, Sodexo, and Compass Group (Martin \& Andrée, 2012). This consolidation "has produced a highly concentrated institutional food sector" where any "new entrants to the sector are at a disadvantage because of the established economies of scale and supply chains, and most importantly, capital" (Martin \& Andrée, 2012, p. 168). One of the ways TNCs maintain their domination is that food manufacturers (large food sector corporations in their own right) must pay TNCs in order to access the institutions the TNCs serve (Foodservice director, 2001 as cited in Martin \& Andrée, 2012). Although many consider TNCs a barrier to creating a more sustainable and equitable food system, others see opportunities that drive change within the system.

The University of Toronto's call for proposals to supply a certain amount of locally sourced and sustainably produced food illustrates that it is the very competition between firms that can push TNCs in the direction of supporting local economies and environmental sustainability. As Martin and Andrée (2012) state, "extremely tight competition and profit-seeking strategies in this field mean that all three players are willing to change their purchasing practices when required by a call for tenders" (p. 169). However, although TNCs' corporate culture of lower costs and mass scale makes them very resistant to change, the cultures of the institutions they serve, such as universities, can push them toward more equitable and environmentally sustainable purchasing (Martin \& Andrée, 2012). But even though universities may be under pressure from their students or other groups to change their contracts with TNC food providers, implementing this change puts the TNC in the difficult position of increasing expenses while diminishing revenue. Nonetheless, Martin and Andrée (2012) point out that there is space for social movement practitioners and organizations to work with institutions to bend contracts toward their goals. The problem with "extremely tight competition and profit seeking" among these firms is that, at some point, these TNCs will look to curtail their costs, which will put pressure to move back toward low-skilled mass production. To counteract such a reversal, Martin and Andrée (2012) propose "third-party certifiers" as a "way forward to initiate institutional contracts and to protect local farmers from the pressures exacted by these companies" (p. 171).

Ecological modernization is a competing theoretical perspective used to understand how more sustainable food systems could be promoted. Ecological modernization theorists see a steady positive change being created by governmental policy that steers industry and individuals in a positive direction instead of heavy-handed, topdown regulation (Obach, 2015). For example, "the USDA does not mandate that all food is grown organically, but policy does create a framework in which organic production can spread" (Obach, 2015, p. 9). From this, the free market and, in this case, TNCs can be "central actors in advancing ecological sustainability" (Obach, 2015, p. 8). According to ecological modernization theory, it is due to consumer demand that firms like TNCs are bringing more ecologically sound food to market. Its proponents also suggest that smaller entrepreneurs, who are successful in their ecologically and socially just food products, help to enlighten and steer business leaders toward these types of goods. In this framework, the role of TNCs and their leaders is to "use their vast resources and advanced technologies to develop new ways" (Obach, 2015, p. 8) to bring these products to consumers. Ecological modernization theorists also imply that TNCs play a role in educating the public through advertising their more sustainable food. The framework also assumes that large firms, like TNCs, help to build the organic and sustainable market and make these goods more accessible to more consumers through competition and consumer demand (Obach, 2015). In other words, corporate players can be seen as "helpful allies in the shift toward a more sustainable social order" (Obach, 2015, p. 8).

\section{Grassroots Reform and Education}

While social change can certainly occur within the industrial food system (Anderson, 2008), grassroots action and ongoing education is necessary to 
advance and sustain change. In fact, engaging in grassroots education appears to be a necessary precursor to making change and, as Hendrickson and Heffernan (2002) suggest, it builds community and social bonds that the industrial system finds hard to replicate. Where TNCs must act to compress time and space (e.g., in a matter of days, salmon is caught in Alaska, shipped to Southeast Asia for processing, and then shipped to New York City for consumption), those who are having success in building alternatives do the opposite. They engage in localizing time and space, in informal education that is time-intensive and context-specific. As Travaline and Hunold (2010) note, participation in environmental civic associations "reproduce(s) and reconstitute(s) relationships" (p. 587) while building effective social and political skills. Similarly, the education that occurs takes place within the context of building relationships and is bound by the social and ecological elements of place (Hendrickson \& Heffernan, 2002). In other words, Hendrickson and Heffernan (2002) claim that, in order to be successful, those seeking to make long-lasting change must play an entirely different game than the players in the industrial system.

Change makers can draw on the fact that knowledge is being gained in the context of community building. According to Hendrickson and Heffernan (2002), as well as many others writing on the topic over the past several decades (Pollan, 2008), knowledge and its corollary skills have been lost to the industrial food system (Hendrickson \& Heffernan, 2002). This includes the loss of knowledge about how to grow food (from large farms who now might rely on chemical inputs to small kitchen gardens) to basic cooking skills (due to processed and pre-prepared foods). This loss of knowledge and skills has occurred all along the food chain. The consequences of this loss, according to its proponents, are dependency on entities such as TNCs and the loss of local culture to a homogenized and ultimately alienating culture. On the other hand, since food is such a defining feature of culture, the movement toward sustainable, local food can empower and revitalize communities because it requires situated knowledge and practicing the skills from that knowledge
(Travaline \& Hunold, 2010). Fonte (2008) points out that whenever attempts are made to rebuild local food systems, there is "a strong history of involvement in community development" (p. 206).

Local food networks offer a way to reintroduce knowledge, gain new knowledge that improves the old, and to build social trust, thus combating the problems (like loss of community and self-sufficiency) that many associate with the global food system. For example, the global food system influences the disconnection between generations. Economic pressures, in which the global food system plays a part, contribute to families eating together less frequently. Proponents claim that where communal and family meals occur are often locations where culture is shared, where knowledge, ideas, and community are replicated, negotiated, and made anew (Pollan, 2008).

A powerful place for this transference of knowledge is the family farm. Peterat and MayerSmith's 2006 study illustrates how farms can be places of community rebuilding across generational boundaries by reintroducing lost knowledge. In their study, issues about "land, food, community, society, and environment" were discussed between female seventh grade students and retired farmers (Peterat \& Mayer-Smith, 2006, pp. 108-109). The female students here might not just be a novel element of this particular study; the majority of new farmers are female and a majority of these new female farmers are engaging in small-scale, sustainable, and organic methods (Masterson, 2011; Obach, 2015).

Within the food localization movement, local and traditional knowledge becomes an indispensable resource for the management of agricultural and natural ecosystems (Fonte, 2008). Farmers markets are one of the venues for informal social learning where producers come together to explore, rekindle, debate, and sometimes argue over knowledge and skills. Here, producers also interact with chefs, value-adding producers (e.g., small-scale food-processing enterprises), and consumers. This varied interaction can spur innovation for new products and/or new ways of marketing them. Additionally, farmers markets (i.e., grower and/or producer-only markets) offer communities a way to localize time and space and grow local food 
systems (Hinrichs, Gillespie, \& Feenstra, 2004). Since farmers markets are predicated on face-toface interaction, they provide an ideal space for local actors from a variety of backgrounds to strengthen and build community (Tiemann, 2008; Travaline \& Hunold, 2010). In these ways, local food movements facilitate social capital at the same time it is resourced (Pietrykowski, 2004).

Obviously, the structural inequalities that exist in the industrial food system cannot be solved by working at the local level alone. For one, power differentials are embedded within small communities too (Allen, 2004). Thus, many in this nascent agri-food generation are building community through melding education, social justice, and economic development into their ecologically sustainable agricultural methods (Gottlieb \& Joshi, 2010). While there are many rural initiatives, the much more visible urban efforts receive most of the attention. For example, the work of Will Allen and daughter Erika's Growing Power in Milwaukee and Chicago stands out as iconic among the many initiatives growing rapidly around the U.S. (Gottlieb \& Joshi, 2010). Critical environmental education (CEE) is a key component of many programs, although it is also contentious because of its value-laden goals. One such program, Our School at Blair Grocery (OSBG) in the lower Ninth Ward of New Orleans, uses CEE in combination with action research to empower lowincome African American youth. Empowerment occurs through egalitarian teaching and learning and by questioning the current social order through a praxis of continual critique, reflection, and action (Ceaser, 2012). While working on creating a successful urban farm, OSBG students make connections between poor neighborhoods, food insecurity, and environmental destruction. In Ceaser's 2012 study, students reported gaining a stronger sense of their own agency and a consequential commitment to social and environmental justice (Ceaser, 2012; Travaline \& Hunold, 2010, had similar results in a similar study). ${ }^{1}$

\footnotetext{
${ }^{1}$ OSBG continues to unofficially host youth from the neighborhood in various informal ways, most notably through an ad hoc after school program (conversation with founder
}

\section{Institutional Education and Agency}

From hospital purchasing to the "farm-to-school" movement in elementary and high schools, institutional sustainable food projects have expanded rapidly over the past decade. Local buying initiatives at colleges and universities have also contributed to the movement. Bartlett (2011) reviews the purchasing goals, academic programs, direct marketing and experiential learning of these projects. She finds that these components coalesce to "legitimize environmental, economic, social justice, and health concerns about conventional food" (Bartlett, 2011, p. 101). She argues that these campus projects may serve as "incubators, pioneering new nodes in an alternative food chain for local regions" (Bartlett, 2011, p. 102). Students usually initiate projects, but faculty and administrative support appear necessary for viability and independent oversight. Just as with higher education's pivotal role in other social movements, many students see food as a central point where the interdependent issues of ecological degradation, health problems, and lopsided federal subsidies lead to economic, social, and ecological ills.

Many of the student-led initiatives have produced institutional purchasing policies, but universities vary in which issues draw their attention. Some purchasing documents focus on global environmental health, such as reducing greenhouse gas emissions. Others wish to address social issues, like making fair trade purchasing a priority. For instance, the University of California, Santa Barbara (n.d.), focuses on health rationales to purchase "foods without additives, pesticides, or preservatives" (cited in Bartlett, 2011, p. 105). Emory University, on the other hand, emphasizes environmental issues by committing to purchasing food that is " $75 \%$ locally or sustainably grown" (as cited in Bartlett, 2011, p. 104). While universities and colleges each choose to address these rationales through different purchasing decisions, sustaining these commitments and tracking purchasing can be a more difficult task (Bartlett, 2011). For example, "expansion in fair trade purchases in one year has been noted on some campuses to quietly

Nat Turner, March 28, 2014). 
disappear in subsequent years" (Bartlett, 2011, p. 106). Furthermore, local purchasing may not address anything more than food miles if environmental and social issues are not also included in the criteria. Bartlett (2011) finds that third-party certifications and purchasing audits using clear metrics and consistent monitoring can provide accountability and transparency while maintaining progress toward goals (see also Gottlieb \& Joshi, 2010). While institutional purchasing presents certain challenges, cost increases are consumers' primary concern. However, results vary at this point. Porter (2015) found that students at the University of Vermont were willing to pay a higher price for local and sustainable food, but not much higher. This willingness to pay a premium and how much of a premium varied by indicators such as gender, major, residency, and attitudes about food and price. In order to keep costs down, Bartlett's (2011) research suggests "reducing menu choice or reducing the frequency of expensive menu items" (p. 106).

Perhaps the most significant organization helping to make colleges and universities leaders in the sustainable food movement is the student-run Real Food Challenge (RFC) network where students at over 330 schools are committed to shifting $20 \%$ of school food budget money to "ecologically sustainable, fair, humane, and local food by 2020 " (RFC, n.d, para. 2). As a result of the work of RFC students at University of California (UC) schools, the entire UC system has committed to the $20 \%$ purchasing goal by 2020 with a potential US $\$ 25$ million dollar impact to the local and sustainable food system (Bartlett, 2011; RFC, n.d.).

To reach these goals, achieving and maintaining campus-wide support is essential (Bartlett, 2011; Gottlieb \& Joshi, 2010; Porter, 2015). Campus farmers markets and community gardens are ways of institutionalizing a communal awareness about food issues. In addition to the experiential learning that campus community gardens and farms offer, food-system courses, especially in the liberal arts, raise awareness and garner interest in careers in sustainable food (Bartlett, 2011). Courses often can be personally transformational and contribute to more critical perspectives on conventional food systems. Debate expands and the groundwork is laid for political action and possible regulatory reform (Bartlett, 2011, p. 111; Gottlieb, 2001; Porter, 2015).

Finally, much like the sustainable food movement in general, campus food projects are no longer novel but have reached a stage of commonality on campuses across the country. The current stage will reveal if these projects can succeed and evolve with the pressures that continue to assert themselves. What is known is that projects that have sustained their accomplishments are "built on broad partnerships across academic, operations, and community groups, suggesting that collaborations are the most effective strategy" (Bartlett, 2011, p. 111; see also Joshi \& Gottlieb, 2010).

\section{Student Engagement}

Much like the food projects at many universities, the literature on student engagement reveals the benefit that participation in a community-based food project can hold for students. However, projects must be well planned. Otherwise, students may "individualize social issues" (Gallini \& Moely, 2003 , p. 5), not realizing the structural conditions that underlie personal problems, and therefore resulting in a victim-blaming mentality; (Grossman, Sherard, Prohn, Bradley, Goodell \& Andrew, 2012). In the same way, poorly planned projects may give students an inflated sense of their importance while ignoring community resources (Gallini \& Moely, 2003).

Nonetheless, well-planned experiential learning can have a lasting impact on both students and community. Studies have found that servicelearning courses promote a sense of civic responsibility and academic, community, and interpersonal involvement (Gallini \& Moely, 2003; Greenwood, 2015; Grossman et al., 2012; Knapp, Fisher, \& Levesque-Bristol, 2010; Silmonet, 2008). For example, Gallini and Moely (2003) reported that service-learning courses improved retention and were more academically challenging than similar courses that were not service-learning oriented. In fact, much like the findings in other studies (Grossman et al., 2012), Gallini and Moely (2003) found that academic course content was most important in influencing how engaged students were with the service-learning component of the 
course and its perceived benefit to them. On the other hand, Knapp et al. (2010) found that while the academic component of the course was vital, maximizing the amount of time spent with the group or community was most important to students' perceived benefits.

In addition to increasing awareness about social inequality, service-learning courses, especially those in the environmental sciences, are used to develop values and skills among students, build student competence, and address actual problems within communities (Grossman et al., 2012). In a study that partnered agricultural students with an underserved community in an urban agriculture project, Grossman et al. (2012) found that students felt they "gained valuable academic and experiential knowledge," and that their academic learning was helpful to their community work (p. 179). Overall, service learning appears to be at its best when "students and community members learn to cocreate knowledge and skills" (Grossman et al., 2012, p. 194).

\section{Methodological Approach}

Although this is a reflective essay, we wish to give a broad outline of the methodological perspective we took on this project. To accomplish our goals, we incorporated principles of community-based research (CBR) to assist Reconnect in accomplishing the goal of creating a more local and sustainable food system at our university (Strand et al., 2003). CBR involves the intersection of three principles. First, extensive collaboration between academics and/or practitioners and community members is established. Second, knowledge is validated and promoted, especially that of community members. And third, projects are carried out to create social change for the purpose of social justice. All of our actions for this project were conducted in order to align with the principles of CBR (Strand et al., 2003).

In fulfillment of the first principle, we served at the pleasure of Reconnect. We continually sought their expertise on a number of issues including the history and goal of the project, the relationships that had been built, and challenges they had encountered. In fact, we sought collaboration from them on all ideas and decisions. This collaborative process was made all the easier by the fact that one of the students in our graduate seminar, Bonnie May, was president of Reconnect at the time. After Reconnect lost some active members to graduation the previous spring, May proposed the project idea to the course professor, David Burley, who is also the faculty advisor to Reconnect. The course seminar had a built-in community-based action component and this project was conceived and confirmed between May and Burley before the semester began.

Reconnect's ultimate goal was to procure direct contracts between their farmer cooperative partners and the university foodservice provider, Aramark. Indian Springs Cooperative and Point Coupee Cooperative, the farmer cooperative partners, are predominately African American producers who have historically faced discrimination (Green, Green, \& Kleiner, 2011). They provided insight on technical aspects of agriculture and contracts along with logistical feedback on farmers markets, the signature event of our campaign. Our goal was to build campus support for acquiring sustainable, local food into the university cafeteria, the ultimate goal of Reconnect.

Second, we designed our project to validate and promote the knowledge of our community stakeholders (Reconnect and the farmer cooperatives). In that manner, we sought to have Reconnect, and to a slightly lesser extent, the farmer cooperatives, shape the direction of our actions. For instance, Reconnect offered expertise from their experiences trying to create student-driven change at the university level. They told us their story of attempting to establish a relationship with Aramark and their inability to get the foodservice supplier to meet with representatives from the farmer cooperatives. ${ }^{2}$ During the first two weeks of the semester, as this process progressed, Burley

\footnotetext{
${ }^{2}$ Reconnect said that they went to great lengths to build a positive relationship with Aramark. However, after some initial positive feedback from the vendor's head chef and marketing director, Aramark ceased responding to requests from Reconnect. They eventually argued that their corporate office does not allow them to contract directly with producers and that the farmers should contract with their distributor. This is given some further explanation in the Conclusion section.
} 
and May sought consultation from Darlene Wolnik, an independent market consultant and long-time activist in New Orleans who had served as the deputy director of the New Orleans market organization for a decade. Wolnik recommended hosting a campus farmers market as a way to build student awareness and constituency for Reconnect's project and shared information from her research into market typology. The idea was immediately brought to the student club, the farmer co-ops, and the class, where it was decided we would build an educational campaign culminating in a farmers market to be held in coordination with the first National Food Day on October 24, 2011.

The third CBR principle, social action for the purpose of achieving social change and justice, was addressed in two key areas: (1) providing options to the industrial food system and the social, economic, and ecological problems that can result and (2) creating a space for African American farmers who are dedicated to sustainable practices and who have, historically, struggled against discrimination. Our project helped to create an environment where members of the university community could actively critique the current industrial food system, all while being given the choice for a more sustainable, socially and economically just food system. Porter (2015) found that such campus-wide education was necessary for success. In addition, partnering with Reconnect to host a farmers market would not only build awareness and constituency on campus, but would also become an act of social justice. By creating this space, it would allow these African American farmer cooperatives, whose formation in the 1960s evolved out of the institutional racism they had faced for so long, to generate more visibility and economic opportunity for themselves.

\section{Methodological Approach in Practice}

Again, our goal was to assist Reconnect in achieving their goal to secure direct contracts between the farmer cooperatives and Aramark. Through discussions with both Reconnect and the farmer co-ops, we settled on an educational campaign culminating with hosting a farmers market on October 24, 2011. We would attempt to raise awareness and educate university students, faculty, and staff about the industrial food system versus a local, sustainable food system. In addition, the farmers market would allow us to gauge, somewhat, the effects of our consciousness-raising efforts while creating a space to opt out of the industrial food system. While to some this approach may seem biased, many students had never before thought about the food system. The food that exists on campus and within the wider community was taken by many to be a matter of fact. To question where that food came from, who it benefited, who might not benefit, how it was grown and produced, or that there might be other options was something many of our students had never considered. Many encountered these ideas for the first time with our project.

Our primary method to educate the student body about Reconnect's efforts and the farmers market was by developing a short (eight to ten minutes) presentation to give in different undergraduate classes. Informational tabling was discussed as another option for education. However, a lack of time by the graduate students and Reconnect members minimized this option. It was also thought to be inefficient. Attracting the attention of students when tabling is difficult especially when competing with other groups, like fraternity and sorority organizations, who might be fundraising or raising money for charity. As a result, we thought we could reach many more students through class presentations. Tim McCarty and Erica Dickerson contacted instructors of a variety of courses by subject and size to ask if they could make a presentation in their classes. From late September to October 24 (the date of the market), presentations were given in 24 undergraduate classes and to two student organizations. McCarty and Dickerson were responsible for contacting instructors, scheduling, and presenting. They also developed the preliminary content of the presentations and the class as a whole gave feedback for final development. Then, Reconnect gave feedback and final approval of the content.

Based as we were in CBR principles, we did not want to lecture students about changing their eating habits. Conversely, we attempted to engage students in an empowering way so that they were encouraged to think critically about where their 
food comes from, to consider opportunities for change, and how they might get involved (Freire, 1993; Strand et al., 2003). Thus, we framed the presentations around a local economic argument that was buttressed by the social and ecological benefits of Reconnect's project. The presentations' development and implementation is explained further in the "Implementation and Discussion" section. At the end of the presentations, a petition advocating for direct contracts with the farmer coops was passed around and students could sign up to get added to a contact list and/or volunteer.

The presentations set the stage for the farmers market, the signature event of our project. To prepare for the farmers market, graduate students in the course divided into groups and took on different tasks, which included doing research on the successful practices of other schools, composing a letter with Reconnect to send to university administration, contacting local news media, emailing students who signed up for the contact list, recording data, and coordinating with Reconnect, farmers, and the university for the market. The graduate students also developed educational and marketing materials and implemented the educational program, in addition to other communication and logistical tasks.

Furthermore, on the day of the market, we held a visual petition where we photographed students who wrote on a small, white dry-erase board why they wanted "real food." ${ }^{3}$ We also conducted an informal convenience survey (a bean survey popular at farmers markets) to get some empirical feedback to include in materials like the letter to university administration. Farmers market customers were asked if they (1) would attend a campus farmers market regularly, (2) would pay a slightly higher cost for local food if it were offered in the campus cafeteria, and (3) if they attend any other farmers markets.

Finally, we needed an efficient way to document all of our tasks. We used an online blog (Imagination Envirostation, 2011) as a journal for

\footnotetext{
${ }^{3}$ Visual petitions are common to Real Food Challenge campaigns at campuses across North America and this project was also loosely affiliated with the RFC.
}

our observations, to collect data, keep track of our tasks and activities, and provide a general forum to share ideas and progress of the project with one another (Burley et al., 2012). Everyone posted updates, the status of tasks, observations, ideas, and concerns to the blog once per week and we discussed posts at our weekly class meetings. This allowed for continual reflection on our goals.

\section{Implementation and Discussion}

To briefly reiterate, Reconnect had been working to obtain a direct contract for the farmer cooperatives to supply produce to the salad bar at the university's cafeteria. A direct contract would give these small producers another market opportunity and, consequently, more income to grow their small operations. This would then support the local and regional economy. Reconnect wished to support local farmers who farmed sustainably, using little to no synthetic pesticides, herbicides, or fertilizers. In essence, the Reconnect students believed these were the practices their money should be encouraging. We agreed with them.

After deciding on the educational campaign and farmers market, we began planning and development. We considered the content of the class presentations and educational materials (informational postcards, fliers, pamphlets, etc.) to be of primary importance and saw them as a place where our sociological skills could be of great use. If the information, or even the design, alienated the person who interacted with the materials, then we would lose potential support. Southeastern Louisiana University is in a politically and culturally conservative area. Due to the politicization of environmental and/or food issues, we decided that to introduce Reconnect's campaign as one of environmental sustainability would not garner nearly as much support as one framed around benefiting our local economy and culture. That is not to say that we downplayed the environmental impact, only that we first made the economic and cultural argument. In preparation, McCarty and Dickerson presented their draft of the presentation to the class and, through a dialogic process, we came up with a narrative about local culture and economy. Agriculture is a part of many students' heritage - many have grandparents or other rela- 
tives who were farmers or had their own kitchen gardens. Consequently, at the beginning of presentations, McCarty, who did most of the presentations due to his ease with public speaking, would ask students about any relatives that farmed and the loss of this way of life in recent decades. This strategy was made more effective because it resonates with the traditional, agricultural-American narrative. However, we were also aware of the exclusionary elements of this narrative. In the popular consciousness, this narrative is almost exclusively white. Although we did not mention race in the presentations, we highlighted the positive impacts of communal knowledge and selfsufficiency that have been historically shared by many African Americans, even in the agricultural South. The presentation then moved into an explanation of how the food on campus was from "mega-farms" in other areas of the country, and we then spoke about Reconnect's efforts to get locally and sustainably produced food into the cafeteria's salad bar. This food was sustainably produced, thus not polluting local air, soil, rivers, or streams. Additionally, many people would rather consume food produced without synthetic chemicals. The issue became about supporting small, local producers who were tied to place and were using ethical practices as opposed to supporting a system that diverted resources away from the regional culture and economy.

At the culmination of each presentation, the date of the farmers market was announced and a sign-up sheet was passed around where students could sign the petition advocating for direct contracts with the farmers and to offer local and sustainable produce at the cafeteria salad bar. Signees could also be added to a contact list and/or volunteer at the market. After speaking to twenty-four classes and two student organizations, 1,079 signatures were gathered for the petition. Six hundred and twenty-eight of signees (58\%) provided their email to add to the contact list and 115 (over 10\%) offered to volunteer. ${ }^{4}$

We also put together educational materials

\footnotetext{
${ }^{4}$ We do not have a total of students who heard the presentations.
}

such as postcards (Figure 1) and pamphlets (Figures 2 and 3). We printed 1,000 postcards and 500 pamphlets with funds from an applied teaching grant from the university. Sole Sanchez and Erica Dickerson researched and designed these materials which were edited and finalized in class discussions. While we had no training in marketing or design, we felt our sociological skills could be applied to these tasks equally, if not better (in the case of marketing), than those trained in those fields. While we thought about what would appeal to the student body, our goal was to educate in an empowering way, not to get people to consume a commodity. For example, one of the proposed facts on the postcards stated that local food travels far fewer miles than industrial food and thus cuts down on carbon dioxide emissions and thus global warming. In class discussions this was changed to, "Locally grown food reduces fossil fuel consumption which decreases dependence on foreign oil" (Figure 1). Again, we are located in an area where the facts of global warming are greatly politicized. The cards still made the point of reducing the consumption of polluting sources of energy while not alienating people based on political ideology. Furthermore, we framed information in the pamphlets around questions about the industrial food system, encouraging readers to think critically about this system and providing ways for them to get involved (Figures 2 and 3). Postcards and pamphlets were distributed at the market to customers and passersby.

\section{The Farmers Market}

The Reconnect Farmers Market took place on October 24, 2011, the first National Food Day. Before the event, there was much work to be done, like registering the event, securing supplies, and getting outside vendor fees waived. Reconnect and Bonnie May took on much of this responsibility.

The market took place from 10:00 am to 2:00 $\mathrm{pm}$ in the outdoor Student Union, a high-traffic area of campus where many groups hold tabling events, making it somewhat difficult to garner the attention of busily passing students. Nonetheless, class participants and Reconnect members noted a certain "buzz" on campus leading up to market day. For example, students recognized McCarty from 


\section{Top reasons to eat locally grown foods:}

1) Local food contains more nutrients, fuller calories, and no preservatives since it is fresh and not ripened on a truck.

2) Eating local food puts more dollars back into our local economy.

3) Fresher produce tastes better and gives your body more energy.

4) Locally grown food reduces fossil fuel consumption which decreases dependence on foreign oil.
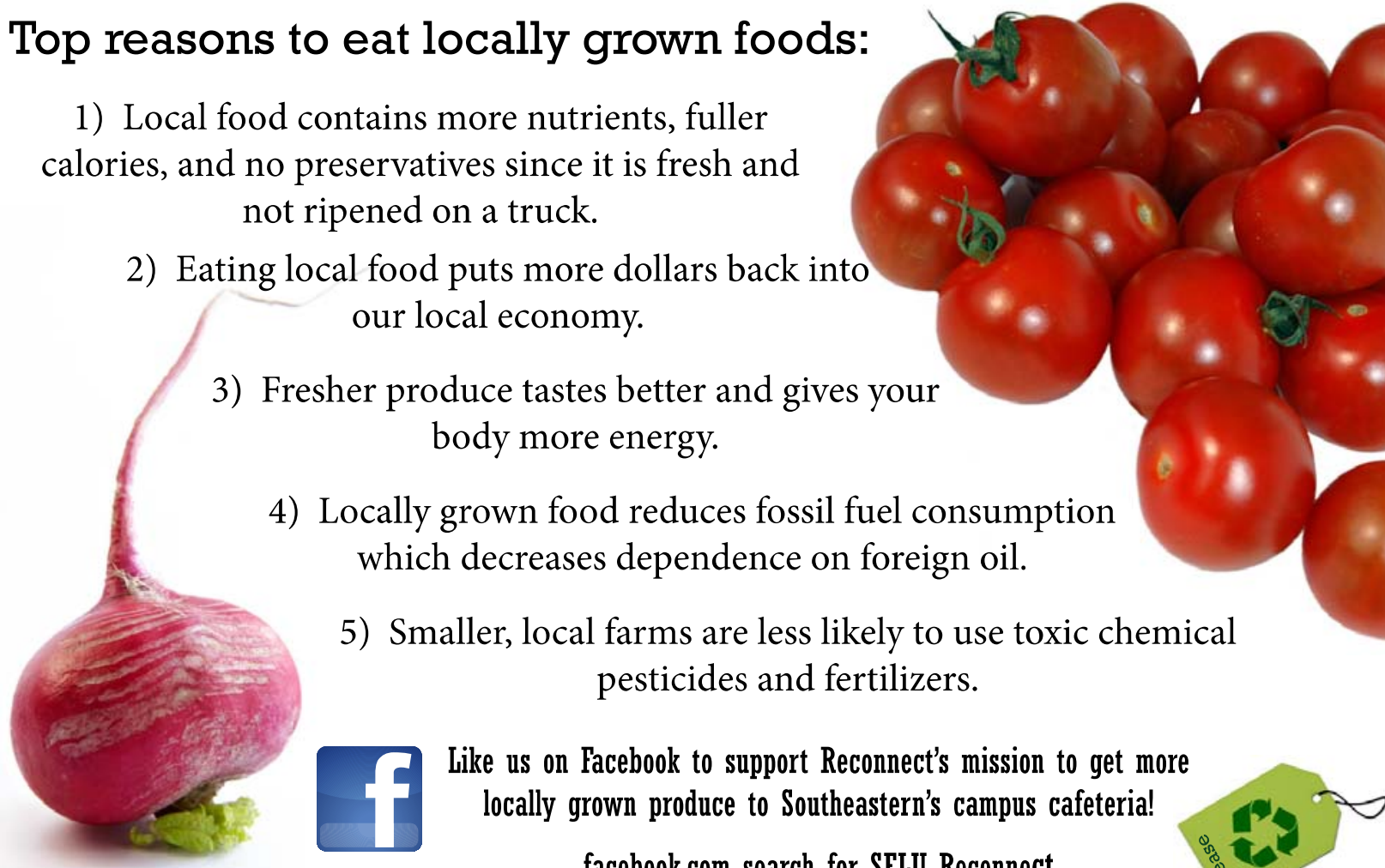

S) Smaller, local farms are less likely to use toxic chemical pesticides and fertilizers.

Like us on Facebook to support Reconnect's mission to get more locally grown produce to Southeastern's campus cafeteria!

facebook.com search for SELU Reconnect

presentations and gave him positive feedback. In addition to our two co-op vendors, we also had a local chef who prepared free samples from the produce. For the photo petition (Figure 4), we collected 37 images of mostly students, but also faculty and community members, who portrayed their reasons for supporting "real food." Reasons included health, taste, our environment, local economy, and community. Photos were uploaded to Reconnect's Facebook page.

Our bean survey of market day customers reflected the positive air surrounding the event. Of the 274 students and staff surveyed, 230 of them said they would be willing to pay slightly more (up to US $\$ 1$ more per meal) for more local produce in the cafeteria. Two hundred and twenty-six said they would attend a regularly held campus farmers market. Our co-op partners were also happy with the success of the market. At our post-market meeting, they expressed their lack of optimism before the market, believing that college students would not be interested. Yet, they were pleasantly surprised by the student reaction. They made a healthy profit and reported that many students had questions about the preparation of the produce or how it was grown, reflecting a desire to regain culturally lost knowledge. One of the farmers from the Point Coupee Cooperative, who had never sold at a public market before, expressed that seeing students smile from interacting with him and the food he grew was one of the more enjoyable experiences of his life. Additionally, students had suggestions for us, the farmers, and Reconnect members about how to make it more convenient for students to purchase fresh produce at future markets.

Again, our farmer co-op vendors were all African American. While we did not collect any data about race, one African American student remarked to one of us that he did not know that "black people farmed." This reflects the popular American narrative of agriculture in the U.S. being 


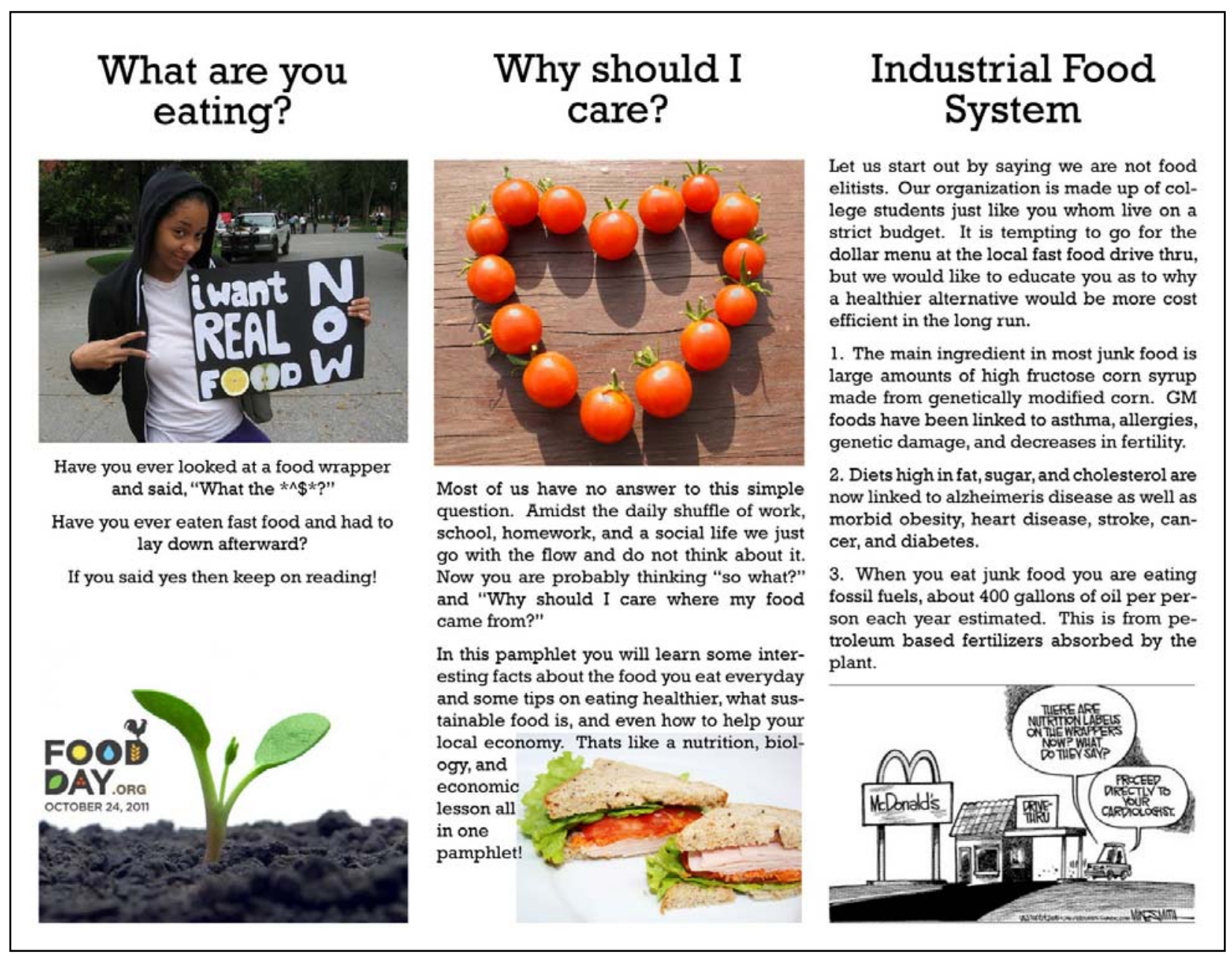

a noble, white-only profession. This socially constructed, historical view of agriculture is a reminder of an oppressive social system for African Americans. It also obscures a more resilient and empowered black history. Post-emancipation, and buoyed by land ownership, farming sustained a black middle class that was engrossed in the social and political issues of the day (Merem, 2006). The presence of these farmers at the market helped to dislodge and reconstruct the traditional narrative while empowering African American students to reconsider their collective story.

After the farmers market, Reconnect submitted a short letter to the university president. The purpose of the letter was to show the economic, social, and ecological impacts of procuring direct contracts with farmers. The letter briefly described
Reconnect's project, the widespread student support the initiative received, and the success had by similar schools in their implementation of these goals. Reconnect never received a reply; however, the Office of Auxiliary Services, who oversees foodservice contracts, contacted Reconnect the following semester and opened a dialogue between the office, Reconnect, and Aramark. To date, nothing noteworthy has come from this dialogue.

The instances we have recounted here are indicative of the success of our educational objectives. Although we did not formally measure the impact of our actions, we believe that the success of the market and the experiences therein reflect certain desires on the part of customers and vendors alike. The educational campaign before and at the market charged interactions and 
Figure 3. Side 2 of the Fold-up Pamphlet

\section{Locally Grown Produce}

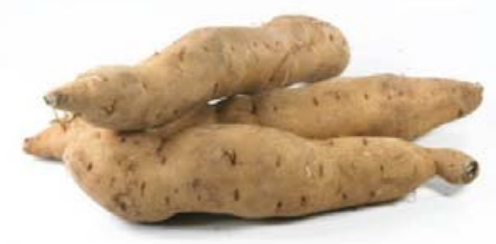

The reasons to shop for local, sustainable food are numerous. Here are just a few:

1. Smaller, local farms are less likely to use toxic chemical pesticides and fertilizers.

2. When you purchase local food the money stays in your local economy which benefits your entire community.

3. Fresher produce tastes better and gives your body more energy.

4. Local food contains more nutrients, fuller calories, and no preservatives since it arrives to you fresh and has not been ripened on a truck.

5. Locally grown food reduces fossil fuel consumption which decreases dependence on foreign oil and saves you the travel cost built into the price.

6. Food with less distance to travel is less likely to become contaminated with biological agents such as salmonella or E.coli.
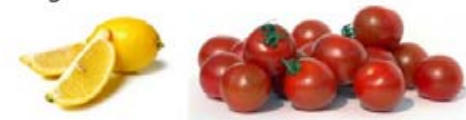

\section{Real Food Challenge}

Reconnect is the student group working to inform other Southeastern students and staff about environmental and sustainability issues. Their goal this year is to persuade $\mathrm{Ar}$ amark to contract directly with local farmers to stock the salad bar in the Cayman Cafe'.

Aramark currently recieves some local food through their distributor, we want them to contract directly with the local farmers to cut out any middle man.

When farms are forced to sell their produce through distributors they make barely enough money to cover costs of growing the food and it takes longer for the food to find its way to your plate since it is now routed through another party.

The mission of Southeastern Louisiana University is to lead the educational, economic and cultural development of southeast Louisiana. One easy way to fulfill this mission is to support the local economy by buying local produce and keeping local farmers in business. When produce is consumed locally up to 80 cents of each dollar stays in the local economy.

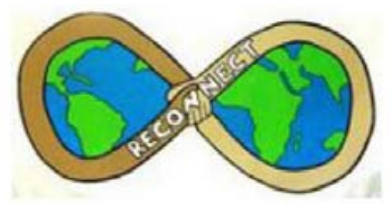

\section{Get Involved \& Make a Difference}

1. Tell your friends about real food.

2. Write a letter to the editor of the Lion's Roar newspaper.

3. Attend Reconnect meetings every other Tuesday.

4. Sign the petition to get real food on SELU's campus and get others to sign up.

5. Volunteer at the food day farmers market.

6. Join Reconnect on facebook for more news and activities!
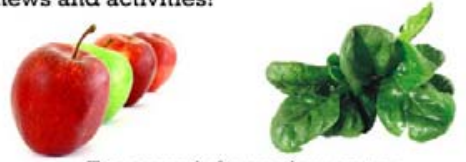

For more information go to: realfoodchallenge.org foodday.org facebook.com search for SELU Reconnect

Sources:

Poulter, Sean. 2008, "Why eating GM food cold lower your fertility." Mail Online. Retrieved Septem ber 26, 2011.

Cascio, Jamais. 2007. "The Cheeseburger Footprint." Open the Future. Retrieved September 26,2011 .

Vieru, Tudor. 2008. "Junk Food Triggered Alzheimer's in Mice." Softpedia. Retrieved September 26, 2011.

Maiser, Jen. 2005. " 10 Reasons to Eat Local Food." Fogcity Blogs. Retrieved September 26 2011.

Pretty, Jules. "Some Benefits and Drawbacks of Local Food Systems." Briefing Note for TVU/Sustain AgriFood Network. Retrieved September 26, 2011. purchases with what Dolan (2009) argues is a "spirit of relationality," where the sort of fair trade that takes place is the subject, rather than the object, of exchange. In fact, the farmers market served to displace the dominant ideology of the neoliberal economy. Market transactions took on different meanings from that of global capitalism, meanings that were integral to place and that produced a "conceptual shift" from alienated exchange (think shopping at Wal-Mart or Target) to exchange that was relationship-oriented and more meaningful (Gagné, 2011). This involved slowing down time and place, something, as noted above, the industrial system finds hard to replicate (Hendrickson \& Heffernan, 2002). The enthusiasm by customers (students and staff) reflected the consciousness of the participants, reinforced by the market experience, which very likely arose out of a desire for a more meaningful form of exchange (Gagné, 2011).

\section{What We Learned}

As with any type of participatory practice, our actions not only had external impacts, but they changed us as well. By being engaged in the process of helping to create social change, we got to put what we had been learning in our masters' program into practice. We had to work with each other, Reconnect, and a diverse group of stakeholders while continually reflecting on our own actions to make sure we were keeping with project goals. We had to learn about others before offering our advice. All stakeholders had different areas of expertise. Thus, we had to appreciate others' 
expertise first. In academia, it is tempting to take the normative role of expert without engaging in dialogue. However, in our case, it may have been a bit easier to sidestep this temptation because, except for Burley, we had no extensive expertise in these areas and were researching and learning as we went.

Particularly, for May, it was her dual role that made it difficult for her to determinate where her responsibilities as Reconnect president ended and where her responsibilities as a graduate student began. While these roles helped her hone her organizing skills, the blurred boundaries of her dual roles were an issue that was never fully rectified.

Nevertheless, we learned the power of organizing. Community was one outcome of this organizing. We developed a sense of community with Reconnect, the farmers, and other students on campus while our class cohered as we became invested in the process. A sense of community also evolved between us and students and staff at other schools engaged in similar projects, who gladly shared their experiences.

\section{Conclusion}

Were we able to get local, sustainable food into our university's cafeteria? No, but we did accomplish a great deal. We used CBR to help a student group achieve its goals; we lent our sociological skills to Reconnect while its members educated us about the "how" and "why" of their campaign; and we used our expertise to make a case for social change to our university community.

Nonetheless, there were some limitations to our project. CBR is process-driven where community members must be intimately involved in "every stage of the research process" (Strand et al., 2003, p. 8). Even though this could be said of Reconnect President Bonnie May, sometimes Reconnect members let us carry out our ideas with little of their own participation. This was mostly due to club members' busy school and work schedules. However, they were not involved in such a way that would have educated them to the research process, including writing final reports (such as this paper), as CBR calls for. Also, during the education campaign, more focus needed to be put on amassing support from other student organizations. We did not put forth enough effort in this regard and there are plenty of organizations that could have provided their backing and brought more publicity to the project. Methodologically, we needed more emphasis on the creation of a way to accurately measure community building. Lastly, we did not adequately use the many people who offered to volunteer for the market. Not only would they have provided more help and reduced the workload on us, but it was also a missed opportunity for them to build community and become invested in the project.

Even though there were missed opportunities to reflect upon and learn from (as there always are in CBR), we achieved a great deal. Although much of the time Reconnect members let us implement our ideas without their direct input, they were deeply involved in executing the farmers market. This involvement gave them real experience in creating social change and, as they conveyed to us, a tremendous sense of fulfillment (as it did us). Because of this excitement and success, Reconnect and the farmer vendors established a campus farmers market to run twice a semester. The Reconnect Farmers Market continues to be entirely studentrun and, for a time, was the only farmers market on a college campus in Louisiana. In fact, other area universities called us to ask about starting their own markets. In addition, the sociology department created an internship, under Burley's direction, for an undergraduate student to act as market manager each semester (Farmers Market Manager Internship, n.d.). This has been a successful, hands-on training and educational tool that, according to feedback from interns, inspires students and gives them direction for their careers and lives.

This project also highlights the role that social scientists can play in creating social change. From the outset, our training allowed us to plan the project from a position where our community partner was in control and where each party had their own expertise from which the other could learn from. Using our sociological training, we continually reflected upon the project to ensure we maintained the egalitarian and participatory principles of CBR. Our sociological skills also allowed us to develop an educational campaign that was, as 
noted earlier, inclusive and appealing to diverse students at our particular university. As Grossman et al. (2012) recommend in their study about student engagement in urban agriculture, there is a "critical need for individuals who understand how best to conduct outreach and educational activities" (Grossman et al., 2012, p. 193). Sociology students with service-learning experience are well equipped to fill this need.

Additionally, there seems to be a welcoming nature to this and most campus food projects that offer students involvement in positive social and environmental change (Bartlett, 2011; Porter, 2015). Many campus or environmental activist activities implore students to cease some activity. However, food projects like the one on our campus offers students the opportunity to create something that is beneficial across multiple spheres and is predicated on relationships and community building. Also, the confidence and skill base that seminar and club students developed can lead to a sense of competence to shape their own future as part of a community (Travaline \& Hunold, 2010).

Regarding the progress of this project, the market continues to run each semester, though Aramark still refuses to contract directly with producers. They argue that, as a matter of corporate policy, they do not contract directly with producers. Aramark has said that the farmers should contract with their distributor to reach our university. Yet the farmers argue that this would nullify any economic gain that might come from getting their food into the university. Projects like this one would benefit from future research into the particularities of why it is difficult for corporate food vendors to contract directly with small, local producers.

In spite of this lack of progress, an opportunity has come from a small café in the university recreation center. The Pride Cafe is the only food facility on campus not operated by Aramark. After recognizing the success of the market, the café manager approached Reconnect and its advisor, Burley, about creating a partnership with a local farm. Reconnect has been working with the cafe and a local, sustainable farm to offer their products at the cafe. While we didn't help Reconnect achieve their ultimate goal, we have created social change that has produced yields beyond our class project. And this change is helping to create a more equitable food system economically, socially, and ecologically.

\section{References}

Allen, P. (2004). Together at the table: Sustainability and sustenance in the American agrifood system. University Park, Pennsylvania: Pennsylvania State University Press.

Anderson, M. (2008, June 7). State of the art food system sustainability metrics. Paper presented at the annual meeting of the Agriculture, Food \& Human Values Society, New Orleans, Louisiana.

Bartlett, P. F. (2011). Campus sustainable food projects: Critique and engagement. American Antbropologist, 113(1), 101-115. http://dx.doi.org/10.1111/j.15481433.2010.01309.x

Bell, M. M. (2012). An invitation to environmental sociology (4th ed.). Los Angeles: Pine Forge Press, SAGE.

Burley, D., Daunis, C., Walker, J., Shelton, N., Cuifi, J., Coleman, M., \& Matheu, B.-F. (2012). Imagination enviro-station: Students connecting students to ecological sustainability. Journal of Rural Social Sciences, 27(2), 50-71.

Ceaser, D. (2012). Our School at Blair Grocery: A case study in promoting environmental action through critical environmental education. The Journal of Environmental Education, 43(4), 209-226. http://dx.doi.org/10.1080/00958964.2011.637094

Dolan, C. S. (2009). Virtue at the checkout till: Salvation economics in Kenyan flower fields. In K. E. Browne \& B. L. Milgram (Eds.), Economics and morality: Anthropological approaches (pp. 167-185). Lanham, Maryland: AltaMira Press.

Estabrook, B. (2012). Tomatoland: How modern industrial agriculture destroyed our most alluring fruit. Kansas City, Missouri: Andrews McMeel Publishing.

Farmers Market Manager Internship. (n.d.). In Southeastern Louisiana University. Retrieved August 20, 2015, from http://www.southeastern.edu/acad_ research/depts/soc_cj/programs/farmers_market/ index.html

Fonte, M. (2008). Knowledge, food and place. A way of producing, a way of knowing. Sociologia Ruralis, 48(3), 200-222. http://dx.doi.org/10.1111/j.14679523.2008.00462.x 
Freire, P. (1993). Pedagogy of the oppressed. New York: Continuum International Publishing Group.

Gagné, N. O. (2011). Eating local in a U.S. city: Reconstructing "community"-a third place-in a global neoliberal economy. American Ethnologist, 38(2), 281-293. http://dx.doi.org/10.1111/j.15481425.2011.01306.x

Gallini, S. M., \& Moely, B. E. (2003). Service-learning and engagement, academic challenge, and retention. Michigan Journal of Community Service Learning, 10(1), 5-14. Retrieved from http://hdl.handle.net/2027/spo.3239521.0010.101

Gottlieb, R. (2001). Environmentalism unbound: Exploring new pathways for change. Cambridge, Massachusetts: MIT Press.

Gottlieb, R., \& Joshi, A. (2010). Food justice. Cambridge, Massachusetts: MIT Press.

Green, J. J., Green, E. M., \& Kleiner, A. M. (2011). From the past to the present: Agricultural development and black farmers in the American south. In A. H. Alkon \& J. Agyeman (Eds.), Cultivating food justice: Race, class, and sustainability (pp. 47-64). Cambridge, Massachusetts: MIT Press.

Greenwood, D. A. (2015). Outcomes of an academic service-learning project on four urban community colleges. Journal of Education and Training Studies, 3(3), 61-71. http://dx.doi.org/10.11114/jets.v3i3.663

Grossman, J., Sherard, M., Prohn, S. M., Bradley, L., Goodell, S., \& Andrew, K. (2012). An exploratory analysis of student-community interactions in urban agriculture. Journal of Higher Education Outreach and Engagement, 16(2), 179-196. Retrieved from http://openjournals.libs.uga.edu/index.php/iheoe/ article/view/794

Hendrickson, M. K., \& Heffernan, W. D. (2002). Opening spaces through relocalization: Locating potential resistance in the weaknesses of the global food system. Sociologia Ruralis, 42(4), 347-369. http://dx.doi.org/10.1111/1467-9523.00221

Hinrichs, C. C., Gillespie, G. W., \& Feenstra, G. W. (2004). Social learning and innovation at retail farmers' markets. Rural Sociology, 69(1), 31-58. Retrieved from http://onlinelibrary.wiley.com/ doi/10.1526/003601104322919892/full

Imagination Envirostation. (2011). Retrieved from http://imaginationenvirostation.blogspot.com

Knapp, T., Fisher, B., \& Levesque-Bristol, C. (2010). Service-learning's impact on college students' commitment to future civic engagement, self- efficacy, and social empowerment. Journal of Community Practice, 18(2/3), 233-251. http://dx.doi.org/10.1080/10705422.2010.490152

Martin, S. J., \& Andrée, P. (2012). The "buy local" challenge to institutional foodservice corporations in historical context. Journal of Agriculture, Food Systems, and Community Development, 2(3), 116-175. http://dx.doi.org/10.5304/jafscd.2012.023.008

Masterson, K. (2011, March 30). U.S. sees more female farmers cropping up. National Public Radio. Retrieved from http://www.npr.org/2011/03/ 30/134979252/u-s-sees-more-female-farmerscropping-up

Merem, E. (2006). The loss of agricultural land among Black farmers. The Western Journal of Black Studies, 30(2), 1-17. Available from https://www.questia. com/library/journal/1G1-185653535/the-loss-ofagricultural-land-among-black-farmers

Obach, B. K. (2015). Organic struggle: The movement for sustainable agriculture in the United States. Cambridge, Massachusetts: MIT Press. http://dx.doi.org/ $10.7551 /$ mitpress / 9780262029094.001 .0001

Peterat, L., \& Mayer-Smith, J. (2006). Farm friends: Exploring intergenerational environmental learning. Journal of Intergenerational Relationships, 4(1), 107-116. http://dx.doi.org/10.1300/J194v04n01 12

Pietrykowski, B. (2004). You are what you eat: The social economy of the Slow Food Movement. Review of Social Economy, 62(3), 307-321. http://dx.doi.org/10.1080/0034676042000253927

Pollan, M. (2008). In defense of food: An eater's manifesto. New York: Penguin Press.

Porter, J. (2015). Get real: An examination of the Real Food Challenge at the University of Vermont (master's thesis). Retrieved from http://scholarworks.uvm.edu/graddis/412

Real Food Challenge. (n.d.). Retrieved August 20, 2015, from http://www.realfoodchallenge.org

Reconnect. (n.d.). Retrieved August 20, 2015, from https://www.facebook.com/ReconnectSouth easternLA? fref $=$ ts

Schnaiberg, A. (1980). The environment: From surplus to scarcity. New York: Oxford University Press.

Simonet, D. (2008). Service-learning and academic success: The links to retention research. Minnesota Campus Compact. Retrieved from https://wmich.edu/ sites/default/files/attachments/u5/2013/ServiceLearning and Academic Success.pdf 
Strand, K. J., Marullo, S., Cutforth, N., Stoecker, R., \& Donohue, P. (2003). Community-based research and higher education: Principles and practices. San Francisco, California: Jossey-Bass.

Tiemann, T. K. (2008). Grower-only farmers' markets: Public spaces and third places. The Journal of Popular Culture, 41(3), 467-487. http://dx.doi.org/10.1111/j.15405931.2008.00531.x

Travaline, K., \& Hunold, C. (2010). Urban agriculture and ecological citizenship in Philadelphia. Local Environment, 15(6), 581-590.

http://dx.doi.org/10.1080/13549839.2010.487529 